\title{
The Comprehension of English Relative Clauses by Arabic-Speaking EFL Learners
}

\author{
Sofia Sabahat Khan ${ }^{1}$ \& Lubaba Abdul-Salam Al-Namer ${ }^{1, *}$ \\ ${ }^{1}$ English Department, College of Education, Humanities, and Social Sciences, Al Ain \\ University of Science and Technology, PO Box 64141 Al Ain, UAE \\ *Corresponding author: English Department, College of Education, Humanities, and Social \\ Sciences, Al Ain University of Science and Technology, PO Box 64141 Al Ain, UAE. Tel: \\ 971-508-361-356_E-mail: lubabah.alnamer@gmail.com,201410808@aau.ac.ae
}

Received: March 16, 2017 Accepted: March 21, 2017 Published: March 29, 2017

doi:10.5296/ije.v9i1.11025 URL: https://doi.org/10.5296/ije.v9i1.11025

\begin{abstract}
This study investigates the extent to which 50 Arabic-speaking EFL learners comprehend English relative clauses (RCs). It also aims to test which relative pronoun among the seven pronouns we are investigating is the easiest to comprehend and which is the most problematic. Furthermore, it aims to measure whether the English proficiency level of the participants affects their performance on the test. Therefore, a multiple-choice test was administered in order to examine their comprehension of this complex syntactic structure. The participants were asked to choose the correct answer out of four choices. The results demonstrate that Arabic-speaking EFL learners may not be fully aware of English relative clauses (total percentage $=48.5 \%$ ). The t-test shows that the English proficiency level affected the participants' performance on the test. Consequently, there is a significant difference between the answers of the advanced learners (ALs) (61.3\%) and those of the intermediate learners (ILs) $(35.6 \%)$. Moreover, the results reveal that the easiest relative pronoun to comprehend is the pronoun when, and the most difficult one is the pronoun whom. This study accounts for these difficulties and concludes with pedagogical implications and recommendations for further research.
\end{abstract}

Keywords: relative clauses, comprehension, Arabic-speaking EFL learners, relative pronouns 


\section{Introduction}

English relative clauses (RC) can often be a stumbling block for EFL learners, due to their complex nature (Rattanasak \& Phoocharoensil, 2014). Although RCs are ubiquitous to all languages, they are expressed in various ways in each language. Some languages make use of relative pronouns and complementizers (e.g. English) (Alroudhan, 2016); some may use pre-verbal relative pronouns in conjunction with post-verbal resumptive pronouns in an encasing construction (e.g. Arabic) (Alroudhan, ibid), whereas others tend to use case-marked relative pronouns to relativize the head noun (e.g. German) (Brandt, Diessel \& Tomasello, 2008). Consequently, the diverse syntactic structures existing in different languages may pose difficulties to learners when attempting to grasp grammatical constructions. Due to their complex nature, a number of studies have explored the acquisition of this phenomenon by EFL learners, yet little attention has been given to the acquisition of this phenomenon by Arabic-speaking EFL learners. Thus, the present study attempts to examine the comprehension of English relative clauses by Arabic-speaking EFL learners, Emirati in particular, taking into consideration their English proficiency level.

\section{Literature Review}

\subsection{Relative Clauses}

A relative clause (RC) may simply be defined as a subordinate or dependent clause that provides additional information to the head noun of the main clause which precedes it. In other words, it acts as an adjective, describing the noun phrase (NP) of the matrix clause, otherwise known as the main or independent clause (Alroudhan, 2016). Relative clauses are of two types in English: restrictive relative clauses (defining) and non-restrictive relative clauses (non-defining). Restrictive relative clauses are not enclosed by two commas on either side of them, whereas non-restrictive relative causes are. This seemingly insignificant bit of punctuation has major implications with regard to the semantic meaning of the sentence. For example, the relative clause in the sentence 'Sally's brother, who lives in Germany, is a doctor' indicates that Sally has only one brother and, the fact that he is a doctor is additional information. If the relative clause was not enclosed by commas on either side, it would read: 'Sally's brother who lives in Germany is a doctor', thus implying that Sally may have more than one brother, but is specifically speaking about the one who lives in Germany. Nevertheless, both restrictive and non-restrictive clauses in English must include a relative pronoun. The only position in which the relative pronoun is not obligatory is when the constituent to be relativized is in the object position (Rokni \& Rahmani, 2012), and are referred to as reduced relative clauses. For instance, in the following sentence, the use of a relative pronoun in brackets is optional, given that the child is in the object position: the child (whom/that) I saw was very skinny.

Previous SLA literature has categorized English RCs into four main types: SS, where both the head noun to be relativized and the gap are in the subject position; SO, where the head noun is the subject and the gap is the object; OS, where the head noun is the object and the gap is 
the subject; and OO, where both the head noun and the gap are in the object position (Hamilton, 1994). Examples of these types are shown as follows:

1. The photographer, who is ill, will not attend the wedding. (SS)

2. The house in which Jack lives is very old. (SO)

3. Sally likes the dog that bit John's leg. (OS)

4. I carried the child, whom the dog bit. (OO)

Keenan and Comrie's extensive study of the structures of relative clauses, based on around fifty different languages, provides an insight into the "ease of comprehension" (1977) of relative clauses, depending on the relativized position of the noun phrase (NP). The Noun Phrase Accessibility Hierarchy (NPAH) implies that every language must have the capacity to first relativize the positions at the top of the hierarchy before those directly beneath them in ascending order. Therefore, the subject position is at the top of the hierarchy, since it is considered to be the easiest to relativize and comprehend, whereas the object of comparison is placed at the opposite end of the scale, given that it is thought to be the most difficult. The NPAH categorizes relative clauses into six types:

Subject $(\mathrm{S})>\operatorname{direct}$ object $(\mathrm{DO})>$ indirect object $(\mathrm{IO})>$ object of adposition $(\mathrm{OADP})>$ genitive $(\mathrm{GEN})>$ object of comparison $(\mathrm{OCOMP})$

(Keenan \& Comrie, 1977)

Here, ' $>$ ' indicates that the position on the left is easier to relativize than the position on the right. Examples of each of the six types are given below:

1. Noah's sister who lives in France is a teacher. (Subject)

2. I carried the child, whom the dog bit. (Direct object)

3. The man, to whom she gave the flower, is very handsome. (Indirect object)

4. The house in which Jack lives is very old. (Object of adposition)

5. The student, whose exam the teacher marked, is very intelligent. (Genitive)

6. The bike, than which the car is faster, was stolen yesterday. (Object of comparison)

The afore-mentioned extensive studies have paved the way for a number of research studies to be carried out to in order to ascertain the difficulties faced by learners of English of different linguistic backgrounds (e.g. Abdolmanafi \& Rahmani, 2012; Rattanasak \& Phoocharoensil, 2014; Gao, 2014; Alotaibi, 2016). Furthermore, these subsequent research studies have shed light on solutions to problems encountered by EFL learners when studying English RCs. The next section reviews a number of studies that tackled the acquisition of English relative clauses by EFL learners who belong to different linguistic backgrounds.

\subsubsection{Previous SLA Research on English Relative Clauses}

Abdolmanafi and Rahmani (2012) investigated the learnability of English relative clauses by 78 male and female Persian-speaking EFL learners, of a high intermediate proficiency level in English. Using a sentence-combination task, the researchers attempted to establish which types of relative clauses were the most difficult to process by testing the three different hypotheses, namely: Kuno's PDH (1974); Keenan's Relativized Subject Accessibility 
Hypothesis (1975), which proposes that the head noun as a subject is easier to relativize than if it were an object; and Sheldon's Parallel Function Hypothesis (1974), which posits that those relative clauses which share the same function as the head noun are easier to process. Abdolmanafi and Rahmani (2012) found that although the tests appeared to support all three hypotheses in some way, the results show the strongest correlation with Keenan's hypothesis, in which he claimed that the SS position is the easiest to relativize. However, no explanation was provided as to why this position was the easiest.

Rattanasak and Phoocharoensil (2014) explored the acquisition of English non-restrictive relative clauses (henceforth NRCs) by Thai-speaking EFL learners. Using a sentence-combination task in conjunction with a translation task (Thai-English), the researchers carried out the study on 80, grade 11, Thai-speaking EFL learners of mixed proficiency levels. These participants were then divided into two groups: those of a lower proficiency and those of a higher proficiency level. The study was conducted to measure the extent to which the participants avoided using relative clause constructions. Rattanasak and Phoocharoensil (2014) then analyzed the results based on the predictions outlined by the NPAH and Kuno's Perceptual Difficulty Hypothesis (PDH) (1974), which is based on the idea that the fickleness of the human memory system makes centrally embedded relative clauses more difficult to process. The results show a high percentage of avoidance, particularly, when dealing with the 'object of adposition' and 'genitive' clauses. In contrast, there was a higher percentage of correct answers when the participants were asked to relativize the 'subject'. However, no explanation was provided as to why this was the easiest. Furthermore, in conjunction with the $\mathrm{PDH}$, participants preferred right embedding to center embedding.

Gao (2014) conducted a study on the acquisition of English RCs by 40 Chinese-speaking EFL learners. The study was carried out to test three different hypotheses: Keenan and Comrie's Noun Phrase Accessibility Hierarchy (NPAH) (1977), Kuno's Perceptual Difficulty Hypothesis (PDH) (1974) and Hamilton's Subject-Object Hierarchy Hypothesis (SOHH) (1994). The SOHH suggests that of the four types of clauses, the hierarchy in terms of ease of acquisition is as follows: $\mathrm{OS}>\mathrm{OO} / \mathrm{SS}>\mathrm{SO}$, where ' $>$ ' implies 'easier to relativize' and '/, indicates 'as easy to relativize as' (Gao, 2014). By adopting the same data elicitation as employed by Izumi (2003), Gao used a sentence combination task in conjunction with a grammaticality judgment test, to test the participants' production and their own intuitive knowledge of RCs, respectively. The results lend support to Kuno's (1974) PDH. The other two hypotheses, however, were not borne out.

In a more recent study, Alotaibi (2016) examined the acquisition of English relative clauses by 120 Kuwaiti EFL learners, 60 of which were ALs and 60 of which were ILs. The aim of this study was to ascertain the extent to which these students were aware of the relative clause structure in English, using a sentence-combination task as his data elicitation tool. He concluded that although both groups made several errors on the task, there was a clear distinction between the participants' proficiency level in English and the number of correct answers that they were able to produce. In light of the NPAH, Alotaibi found that the participants made the least number of errors when asked to relativize the head noun in the 
subject position, thus supporting the hierarchy. With regard to the SOHH, Alotaibi's results show that the easiest type of RC to relativize is the OS. He proposes that this may be due to the fact that participants only needed to replace the head NP with the relative pronoun. Furthermore, he found that the most obvious type of error was in the unnecessary use of the resumptive pronoun, which implies L1 negative transfer. Whereas Alotaibi's study focused on the production of relative clauses by Kuwaiti EFL learners (Alotaibi, 2016), this study aims to examine the extent to which Arabic-speaking EFL learners comprehend English relative clauses using a multiple-choice test (see Altakhaineh \& Rahrouh, 2015). In particular, this study provides the opportunity to compare the receptive and productive skills of Arabic-speaking EFL learners as far as English relative clauses are concerned; thus, determining whether they find the comprehension of these clauses easier than their production or vice versa.

Although much of the previous literature has focused on the acquisition of a number of English phenomena by Arabic-speaking EFL learners (e.g. Altakhaineh \& Zibin, 2014; Alotaibi \& Alajmi, 2015; Alotaibi, 2016; Zibin \& Altakhaineh, 2016 among others), little focus has been given to the comprehension of English relative clauses by Arabic-speaking EFL learners. Therefore, this study aims to fill this gap through exploring this phenomenon.

\subsubsection{Research Questions}

This study aims to provide answers to the following research questions:

1. To what extent do Arabic-speaking EFL learners comprehend English relative clauses?

2. What are the most problematic relative pronouns for Arabic-speaking EFL learners to comprehend?

3. Are there any differences between the performance of advanced and intermediate learners on the test?

\section{Methodology}

\subsection{The Sample}

Fifty students from Al Ain University of Science and Technology, Al Ain, the United Arab Emirates (UAE), participated in the current study. The participants were chosen at random and divided into two groups ( 25 each) on the basis of a single variable, i.e. their English proficiency level. The proficiency level was determined according to the two modules the students had enrolled in: those who were enrolled in Intensive Remedial English (IRE) were considered intermediate learners (ILs), and generally, their IELTS scores were 4 or less, whilst those enrolled in English 2 were considered advanced learners (ALs), subsequently, their IELTS scores ranged between 5 and 6.5. Table 1 below describes the classification of the participants based on their English proficiency level: 
Table 1. The Classification of the Participants

\begin{tabular}{cc}
\hline English proficiency level & Number of participants \\
\hline Intermediate learners (ILs) & 25 \\
Advanced learners (ALs) & 25 \\
\hline
\end{tabular}

The participants were informed that their participation was voluntary and there was no penalty for withdrawal at any time. Moreover, they were assured that the data they provided would be followed up with care. In the end, we thanked them for their participation in the test.

\subsubsection{The Test}

A widely-used data collection tool employed in testing the comprehension of certain expressions by the participants in the target language is the multiple-choice test (Nicol, 2007). Moreover, many scholars have used this particular test to evaluate EFL learners' comprehension of certain phenomena in the target language, since it yields reliable results (Iravani \& Ghasemi, 2012 and Altakhaineh \& Rahrouh, 2015; Zibin, 2016 among others). Hence, this data elicitation tool was selected in the current study.

Since our main focus was to determine which relative pronouns Arabic-speaking EFL learners have most difficulty with, the test consisted of 21 sentences using 7 pronouns, each relative pronoun was represented by three sentences. The choices on the test were as follows: one correct answer (relative pronoun), one incorrect answer, one distractor, and one 'I don't know' option. The last option was employed in order to ensure the reliability of the results (see Altakhaineh \& Rahrouh, 2015; Zibin, 2016). The relative pronouns we focused on were: who, whom, whose, which, that, where, and when. Consequently, the sentences used in the instrument itself were a combination of both restrictive and non-restrictive relative clauses (see Appendix A). In addition, we structured the sentences in a way in which they would also be representative of the six types of the relative pronouns, according to the Noun Phrase Accessibility Hierarchy (NPAH) as outlined by Keenan and Comrie (1977), and Hamilton's (1994) Subject-Object Hierarchy Hypothesis (SOHH) OS, OO, SS, and SO.

\subsubsection{Statistical Analysis}

In order to measure whether the English proficiency level of the participants affected their comprehension of English relative clauses, we carried out a t-test using an SPSS software package. The test measures whether the differences in the answers provided by the participants of the two groups are statistically significant or not. Thus, the test indicates whether or not the proficiency level of the participants positively or negatively contributes to their comprehension of English relative clauses. The following section presents the findings of the current study and compares them with the results of studies that tackled the acquisition of English relative clauses by Arabic-speaking EFL learners. 


\section{MInstitute"}

\section{Results and Discussion}

As discussed in section 3, this study aims to test the comprehension of English relative clauses by Arabic-speaking EFL learners. It also investigates whether there are differences in the performance of ALs and ILs on the multiple-choice test. Table 2 presents the number and percentage of correct answers provided by the ILs on the test, and Table 3 shows those provided by the ALs.

Table 2. Number and Percentage of Correct Answers by ILs on the Test

\begin{tabular}{|c|c|c|c|c|c|}
\hline \multirow[t]{2}{*}{$\begin{array}{l}\text { Relative } \\
\text { Pronouns }\end{array}$} & & $\begin{array}{l}\text { No. of Correct } \\
\text { answers out of } \\
25\end{array}$ & $\begin{array}{l}\text { Percentage of } \\
\text { correct answers } \\
\text { for each item } \%\end{array}$ & $\begin{array}{l}\text { Percentage of } \\
\text { correct answers } \%\end{array}$ & $\begin{array}{l}\text { No. of correct } \\
\text { answers out of } 75\end{array}$ \\
\hline & 1 & 12 & $48 \%$ & & \\
\hline \multirow[t]{3}{*}{ Which } & 2 & 3 & $12 \%$ & $33.3 \%$ & 25 \\
\hline & 3 & 10 & $40 \%$ & & \\
\hline & 1 & 9 & $36 \%$ & & \\
\hline \multirow[t]{3}{*}{ That } & 2 & 7 & $28 \%$ & $30.67 \%$ & 23 \\
\hline & 3 & 7 & $28 \%$ & & \\
\hline & 1 & 11 & $44 \%$ & & \\
\hline \multirow[t]{3}{*}{ Whose } & 2 & 10 & $40 \%$ & $40 \%$ & 30 \\
\hline & 3 & 9 & $36 \%$ & & \\
\hline & 1 & 11 & $44 \%$ & & \\
\hline \multirow[t]{3}{*}{ Where } & 2 & 8 & $32 \%$ & $41.3 \%$ & 31 \\
\hline & 3 & 12 & $48 \%$ & & \\
\hline & 1 & 12 & $48 \%$ & & \\
\hline \multirow[t]{3}{*}{ When } & 2 & 16 & $64 \%$ & $52 \%$ & 39 \\
\hline & 3 & 11 & $44 \%$ & & \\
\hline & 1 & 3 & $12 \%$ & & \\
\hline \multirow[t]{3}{*}{ Whom } & 2 & 3 & $12 \%$ & $17.3 \%$ & 13 \\
\hline & 3 & 7 & $28 \%$ & & \\
\hline & 1 & 10 & $40 \%$ & & \\
\hline \multirow[t]{2}{*}{ Who } & 2 & 9 & $36 \%$ & $34.67 \%$ & 26 \\
\hline & 3 & 7 & $28 \%$ & & \\
\hline $\begin{array}{l}\text { Percentage } \\
\text { correct } \\
\text { answers \% }\end{array}$ & of a & & $35.6 \%$ & & 187 out of 525 \\
\hline
\end{tabular}




\section{IIMacrothink}

Table 3. Number and Percentage of Correct Answers by ALs on the Test

\begin{tabular}{|c|c|c|c|c|c|}
\hline \multicolumn{2}{|l|}{$\begin{array}{l}\text { Relative } \\
\text { Pronouns }\end{array}$} & $\begin{array}{l}\text { No. of Correct } \\
\text { answers out of } \\
25\end{array}$ & \multirow{2}{*}{$\begin{array}{l}\text { Percentage of } \\
\text { correct answers } \\
\text { for each item } \%\end{array}$} & \multirow[t]{2}{*}{$\begin{array}{l}\text { Percentage of } \\
\text { correct answers } \%\end{array}$} & \multirow[t]{2}{*}{$\begin{array}{l}\text { No. of correct } \\
\text { answers out of } 75\end{array}$} \\
\hline & 1 & 22 & & & \\
\hline \multirow[t]{3}{*}{ Which } & 2 & 4 & $16 \%$ & $53.3 \%$ & 40 \\
\hline & 3 & 14 & $56 \%$ & & \\
\hline & 1 & 13 & $52 \%$ & & \\
\hline \multirow[t]{3}{*}{ That } & 2 & 13 & $52 \%$ & $57.3 \%$ & 43 \\
\hline & 3 & 17 & $68 \%$ & & \\
\hline & 1 & 19 & $76 \%$ & & \\
\hline \multirow[t]{3}{*}{ Whose } & 2 & 11 & $44 \%$ & $54.67 \%$ & 41 \\
\hline & 3 & 11 & $44 \%$ & & \\
\hline & 1 & 19 & $76 \%$ & & \\
\hline \multirow[t]{3}{*}{ Where } & 2 & 18 & $72 \%$ & $78.67 \%$ & 59 \\
\hline & 3 & 22 & $88 \%$ & & \\
\hline & 1 & 17 & $68 \%$ & & \\
\hline \multirow[t]{3}{*}{ When } & 2 & 22 & $88 \%$ & $80 \%$ & 60 \\
\hline & 3 & 21 & $84 \%$ & & \\
\hline & 1 & 8 & $32 \%$ & & \\
\hline \multirow[t]{3}{*}{ Whom } & 2 & 9 & $36 \%$ & $33.3 \%$ & 25 \\
\hline & 3 & 8 & $32 \%$ & & \\
\hline & 1 & 17 & $68 \%$ & & \\
\hline \multirow[t]{2}{*}{ Who } & 2 & 22 & $88 \%$ & $72 \%$ & 54 \\
\hline & 3 & 15 & $60 \%$ & & \\
\hline $\begin{array}{l}\text { Percentag } \\
\text { correct } \\
\text { answers \% }\end{array}$ & f al & & $61.3 \%$ & & 322 out of 525 \\
\hline
\end{tabular}

Table 2 shows that the ILs encountered many difficulties in comprehending English relative clauses on the test. Their overall percentage of correct answers was 35.6\%. As far as the relative pronouns were concerned, the highest percentage of correct answers provided by the ILs was on the pronoun when (52\%), while the lowest percentage was on the pronoun whom (17.3\%). Furthermore, Table 3 demonstrates that the ALs also faced difficulties comprehending relative clauses. Consequently, the overall percentage of correct answers was $(61.3 \%)$, which is almost the double of those answers given by the ILs. In addition, the highest percentage of correct answers was on the pronoun when $(80 \%)$, and that corresponded to the results of the ILs. On the contrary, the lowest percentage was on the pronoun whom $(33.3 \%)$.

As demonstrated by the results, the most difficult English relative pronoun for both ILs and ALs to comprehend was whom. On the other hand, the easiest to comprehend were when and 
where. The hierarchy of the ease of comprehension concerning the ILs starting with the easiest relative pronoun and ending with the most difficult one is as shown below:

Chart 1

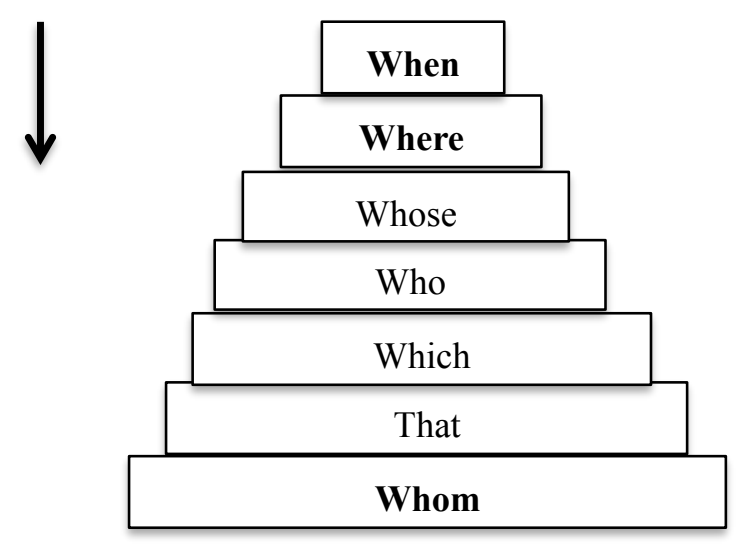

The hierarchy of the ease of comprehension of the ALs commencing with the easiest relative pronoun and ending with the most difficult one is as follows:

Chart 2

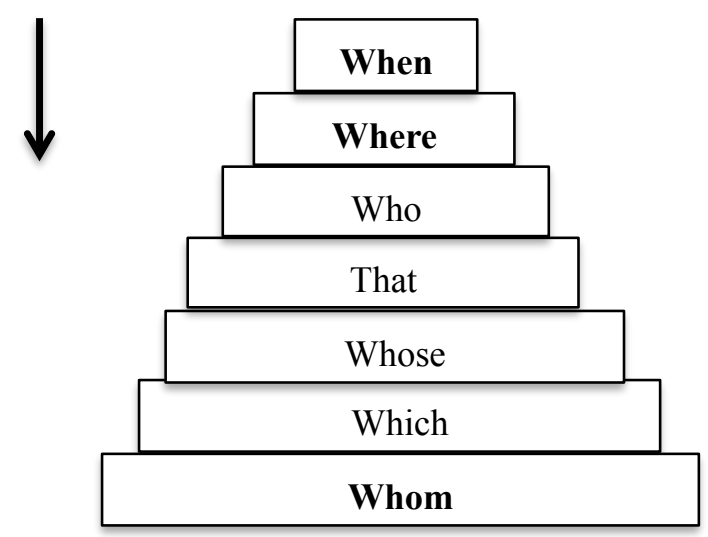

The hierarchy of the ease of comprehension for both the ALs and ILs beginning with the easiest relative pronoun and ending with the most difficult one is as shown below:

Chart 3

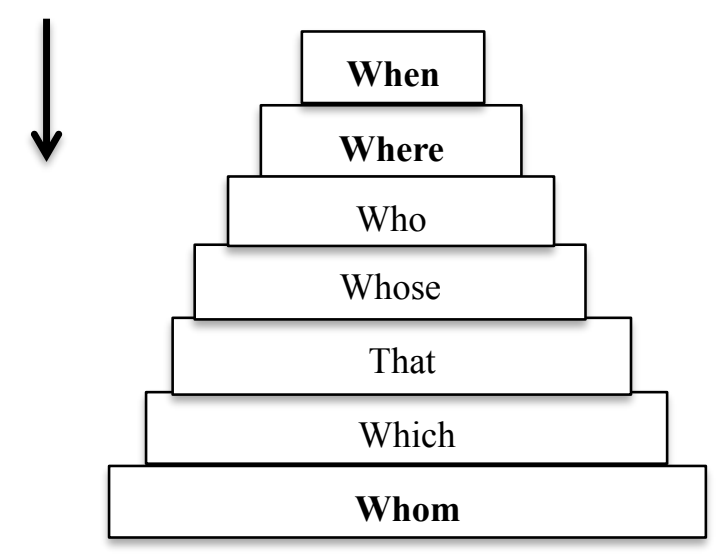


The other four relative pronouns - that, who, which, whose - vary in terms of their order of difficulty for both ILs and ALs. Nevertheless, the ease of comprehension for both groups is similar as far as whom, where, and when are concerned. However, it should be noted that there is no remarkable difference in the percentages of these four relative pronouns. Overall, the results show that both ALs and ILs encountered most difficulty comprehending the relative pronoun whom and the least difficulty with the pronoun when.

In order to test whether there were statistically-significant differences between the performance of the ILs and ALs, a t-test was employed. Table 4 presents the results of the t-test.

Table 4. T-test of the Differences between the Percentage of Correct Answers Provided by ILs and ALs on the Seven Types of Relative Clauses

\begin{tabular}{llllll}
\hline $\begin{array}{l}\text { English } \\
\text { proficiency level }\end{array}$ & Number & Mean & T value & $\begin{array}{l}\text { Degree of } \\
\text { freedom }\end{array}$ & Sig. \\
\hline ILs & 25 & 3.56 & -3.43017 & 6 & $0.024^{*}$ \\
ALs & 25 & 6.13 & & & \\
\hline
\end{tabular}

$* \mathrm{p}>0.05$

Table 4 demonstrates that the difference in the percentage of correct answers provided by the two groups on the seven types of relative clauses was statistically significant; $p$ value was lower than 0.05. This result suggests that the English proficiency level of the ILs and ALs played a role in their comprehension of English relative clauses. Specifically, the ALs outperformed their ILs counterparts on the test.

If we look at the most difficult pronoun, whom, we find that examples (1), (2), and (3) are all almost equally difficult to comprehend. Nevertheless, the results show that the indirect object is the easiest to relativize.

1) I carried the child whom the dog bit. (Direct object)

2) Sally likes Michael, than whom Bob is more athletic. (Object of comparison)

3) The man to whom she gave the flower is very handsome. (Indirect object)

However, if we take a closer look at the results, we find that within the relative pronoun which, the most difficult of the three sentences to comprehend was which (4) - that is object of adposition - for both ILs and ALs:

4) The house in which Jack lives is very old. (Object of adposition)

If we look at the pronoun which, we find that the object of adposition - which (4) - is more difficult to comprehend than the subject and the object of comparison.

5) Emma read the book which has a few pages missing. (Subject)

6) The house in which Jack lives is very old. (Object of adposition)

7) The bike, than which the car is faster, was stolen yesterday. (Object of comparison) 
Whereas Alotaibi focused on measuring the production of Arabic-speaking EFL learners to Keenan and Comrie's NPAH, the current study focuses on determining which pronouns are the most difficult to comprehend. Therefore, if the results of the present study are to be compared to Alotaibi's, in order to attempt to gauge, on a wider level, which are the most problematic pronouns for Arabic-speaking EFL learners, then we must focus on those pronouns which are mutual in both studies. Thus, according to Comrie, the pronouns when and where do not fit in the hierarchy, because they are 'temporal' and 'locative', respectively (Comrie, 1989). Furthermore, he has expounded that in some languages, locative and temporal pronouns are easier to relativize than others (Comrie, ibid). Consequently, the results of the current study show that the temporal and locative pronouns are easy to relativize for Arabic-speaking EFL learners. A possible explanation for this could be that the participants may have comprehended these two pronouns as adverbials of time and place, as opposed to locative and temporal relative pronouns. In addition, just as whose is unique to the genitive (Gass, 1979), one may draw parallels with the fact that where and when are unique to the temporal and locative pronouns, respectively. In further support of this, the head nouns of the matrix clauses for these two pronouns are defining in terms of time and place. In the following examples, the head noun to be modified is underlined, while the pronoun is italicized.

8) The time when Sally was unemployed was a depressing one. (Temporal)

9) The place where Bill parked his car is very unsafe. (Locative)

If we now look at the NPAH, similar to Alotaibi (2016), the results suggest that the easiest of the six types of RCs to comprehend by the participants is the subject. This is in accordance with both the NPAH (Keenan \& Comrie, 1977), which states that a language must first be able to relativize the subject before the other positions on the hierarchy. A possible explanation for why the subject position is easiest to relativize may be that the head noun of the matrix clause is the agent of the verb, which directly follows the relative pronoun.

Furthermore, it is interesting to note, that the genitive, which has been placed as being the penultimate most difficult type of clause to relativize in the NPAH, is the easiest to relativize after the subject, according to the results (see chart 3). One possible explanation for this has been proposed by Gass (1979). She suggests, that the English relative pronoun whose is unique to the genitive. Therefore, it may be suggested that comprehending the genitive is easier given that there are no other ambiguous possibilities.

On the other hand, the results show that the most difficult type of RC to comprehend is the direct object. A possible explanation may be that the direct object usually takes the pronoun whom. However, this pronoun is gradually becoming less common and is increasingly being replaced by who (Görlach, 1999). Therefore, the infrequency of the usage of whom may suggest that the participants were unfamiliar with the pronoun, which was reflected in their answers. This differs from Alotaibi's results, which show that the most difficult of the six types of RCs for Arabic-speaking EFL learners to produce is the object of comparison. This may be due to the fact that Alotaibi was measuring production. Consequently, his data elicitation tool (sentence-combination task) required the participants to produce the relative 
pronoun, thus increasing the number of ambiguous possibilities. On the other hand, the present study employed a multiple-choice test. As a result, this data elicitation tool limited the number of choices. Given that the results support that the subject position is the easiest for Arabic-speaking EFL learners to comprehend, this predicts that the easiest type of the four $\mathrm{RCs}$ in the SOHH will be the subject.

With regard to Hamilton's SOHH (1994), the results of this study show that the SS and OS structures are mutually easy to comprehend, whereas the most problematic type is OO. Thus the ease of comprehension for the $\mathrm{SOHH}$ as displayed by the results is as follows:

\section{$\mathrm{SS} / \mathrm{OS}>\mathrm{SO}>\mathrm{OO}$}

On the whole, the findings of the current study are in accordance with Alotaibi's results, given that according to both hypotheses - the NPAH and the SOHH - the results of both studies show that the easiest type of RC to relativize, for Arabic-speaking EFL learners, is the one where the gap is the subject. On the other hand, with regard to the SOHH, the most problematic $\mathrm{RC}$ to relativize is the one where the gap is the object.

\section{Conclusion and Recommendations}

The main aim of this study was to test 50 Arabic-speaking EFL learners' comprehension of English relative clauses. It also examined which relative pronouns are the easiest to comprehend and which are the most difficult, in addition to measuring the effect of the English proficiency level on this ability. The overall percentage of correct answers for both the ILs and ALs was $48.5 \%$, which indicates that they are not fully aware of English relative clauses. The t-test also showed that there was a statistically-significant difference between the two groups. Therefore, their English proficiency level played a crucial role in their answers on the test. Specifically, the easiest relative pronoun was when $(66 \%)$. On the other hand, the most problematic pronoun was whom $(25.3 \%)$.

Taking these results into consideration, teachers of English as a second/foreign language need to put more emphasis on relative clauses, particularly, on the pronoun whom, since it is the most problematic to Arabic-speaking EFL learners. It is also advisable to teach relative clauses through intensive reading. Moreover, it is important to make the learners familiar with the different structures of all relative clauses, for example, object of adposition. Teachers also need to refer to the NPAH, which plays an important role in the comprehension of the complex structures of relative clauses. This may help the learners be exposed to as much structures of relative clauses as possible, resulting in a better understanding and comprehension of this phenomenon. Finally, it is recommended that studies tackling the acquisition of other phenomena, either syntactic, e.g. wh-questions, or lexical, e.g. compounds (see Altakhaineh 2016), are needed to shed light on the difficulties encountered by Arabic-speaking EFL learners in SLA. 


\section{Acknowledgements}

We are immensely indebted to Dr. Abdel Rahman Altakhaineh for his valuable comments and feedback on the early drafts of the paper. Many thanks also go to all the students who participated in the current study. Any remaining errors are ours.

\section{References}

Abdolmanafi, S. J., \& Rahmani, Z. (2012). An investigation of the learnability of relative clauses by EFL learners. World, 2(3), 29-37. http://dx.doi.org/10.5430/wjel.v2n3p29

Alotaibi, A. M. (2016). Examining the learnability of English relative clauses: Evidence from Kuwaiti EFL learners. English Language Teaching, 9(2), 57-65. http://dx.doi.org/10.5539/elt.v9n2p57

Alroudhan, H. E. (2016). The acquisition of English restrictive relative clauses by Arab adult EFL learners. Advances in Language and Literary Studies, 7(1), 33-53. http://dx.doi.org/10.7575/aiac.alls.v.7n.1p.33

Altakhaineh, A. R. M. (2016). Headedness in Arabic compounds within the synthetic genitive construction. SAGE Open, 6(4), 1-16.

Altakhaineh, A. R. M., \& Rahrouh, H. N. (2015). The use of euphemistic expressions by Arab EFL learners: Evidence from Al Ain University of Science and Technology. International Journal of English Linguistics, 5(1), 14-21. http://dx.doi.org/10.5539/ijel.v5n1p14

Altakhaineh, A. R. M., \& Zibin, A. (2014). Perception of culturally loaded words by Arab EFL learners. International Journal of Linguistics, 6(3), 1-22. https://doi.org/10.5296/ijl.v6i3.4922

Brandt, S., Diessel, H., \& Tomasello, M. (2008). The acquisition of German relative clauses: A case study. Journal of Child Language, 35(02), 325-348.

Comrie, B. (1989). Language universals and linguistic typology: Syntax and morphology. Chicago: University of Chicago press.

Diessel, H., \& Tomasello, M. (2005). A new look at the acquisition of relative clauses. Language, 81(4), 882-906.

Fitzpatrick, E. (2007). Corpus Linguistics beyond the Word: Corpus Research from Phrase to Discourse (Vol. 60). Amsterdam: Rodopi.

Gao, Q. Q. (2014). Chinese EFL learners' acquisition of English relative clauses. International Journal of English Linguistics, 4(3), 82-87.

Gass, S. (1979). Language transfer and universal grammatical relations. Language Learning, 29(2), 327-344. 


\section{IIMacrothink}

Görlach, M. (1999). English in Nineteenth-Century England: An Introduction. Cambridge: Cambridge University Press.

Hamilton, R. L. (1994). Is implicational generalization unidirectional and maximal? Evidence from relativization instruction in a second language. Language Learning, 44(1), 123-157.

Izumi, S. (2003). Processing difficulty in comprehension and production of relative clauses by learners of English as a second language. Language Learning, 53(2), 285-323.

Keenan, E. L., \& Comrie, B. (1977). Noun phrase accessibility and universal grammar. Linguistic Inquiry, 8(1), 63-99.

Kuno, S. (1974). The position of relative clauses and conjunctions. Linguistic Inquiry, 5(1), 117-136.

Nicol, D. (2007). E-assessment by design: using multiple-choice tests to good effect. Journal of Further and Higher Education, 31(1), 53-64.

Rattanasak, S., \& Phoocharoensil, S. (2014). Avoidance in processing English non-restrictive relative clauses in Thai EFL learners' interlanguage. Asian Social Science, 10(17), 265-277. http://dx.doi.org/10.5539/ass.v10n17p265

Suh, J. S. (2000). A difficulty ordering for the learning of English relative clauses. The Journal of English Grammar, 4, 5-22.

Sheldon, A. (1974). The role of parallel function in the acquisition of relative clauses in English. Journal of Verbal Learning and Verbal Behavior, 13(3), 272-281.

Zibin, A. (2016). The comprehension of metaphorical expressions by Jordanian EFL learners. SAGE Open, 6(2), 1-15.

Zibin, A., \&Altakhaineh, A. R. M. (2016). Acquiring the English causative alternation: Evidence from the University of Jordan. International Journal of Applied Linguistics and English Literature, 5(3), 7-15. http://dx.doi.org/10.7575/aiac.ijalel.v.5n.3p.7 
Appendix 1. The Test

\section{Q1. Circle the relative pronoun which best fits the sentence.}

1. Emma read the book has a few pages missing.
a) whose
b) which
c) where
d) I don't know

2. Sally likes the dog, bit John's leg.
a) that
b) where
c) whose
d) I don't know

3. I carried the child, the dog bit.
a) when
b) whom
c) whose
d) I don't know

4. The place Bill parked his car is very unsafe.
a) which
b) that
c) where
d) I don't know

5. Sally likes Michael, than Bob is more athletic.
a) which
b) whom
c) that
d) I don't know

6. The doctor phone broke came to my house.
a) whom
b) whose
c) which
d) I don't know

7. The man, to she gave the flower, is very handsome.
a) whom
b) who
c) that
d) I don't know

8. The photographer, is ill, will not attend the wedding.
a) who
b) whom
c) which
d) I don't know

9. The house in Jack lives is very old.
a) which
b) that
c) where
d) I don't know

10. I saw the elephant escaped from the zoo in my back garden.
a) who
b) that
c) when
d) I don't know

11. The student, exam the teacher marked, is very intelligent.
a) whose
b) whom
c) that
d) I don't know

12. The man helped me last week passed away.
a) where
b) whom
c) who
d) I don't know

13. The builder, tools were stolen, is a hardworking man. 

a) whom
b) that
c) whose
d) I don't know

14. The time Sally was unemployed was a depressing one.
a) where
b) when
c) that
d) I don't know

15. Noah's sister lives in France is a teacher.
a) who
b) whom
c) where
d) I don't know

16. The place Anne had an accident is close by.
a) where
b) which
c) who
d) I don't know

17. The bike, than the car is faster, was stolen yesterday.
a) when
b) who
c) which
d) I don't know

18. Yesterday was the day I was at home alone.
a) where
b) when
c) that
d) I don't know

19. James built the chair I sat on.
a) whom
b) where
c) that
d) I don't know

20. This is the house I was born.
a) which
b) where
c) that
d) I don't know

21. Grandfather remembers a time during the war
a) which
b) when
c) whom
d) I don't know life was very difficult.

\section{Copyright Disclaimer}

Copyright for this article is retained by the author(s), with first publication rights granted to the journal.

This is an open-access article distributed under the terms and conditions of the Creative Commons Attribution license (http://creativecommons.org/licenses/by/3.0/). 